\title{
Using modified poly(3,4-ethylene dioxythiophene): Poly(styrene sulfonate) film as a counter electrode in dye-sensitized solar cells
}

\author{
Jian-Ging Chen ${ }^{\mathrm{a}}$, Hung-Yu Wei ${ }^{\mathrm{b}}$, Kuo-Chuan $\mathrm{Ho}^{\mathrm{a}, \mathrm{b}, *}$ \\ ${ }^{a}$ Department of Chemical Engineering, National Taiwan University, Taipei 10617, Taiwan \\ ${ }^{\mathrm{b}}$ Institute of Polymer Science and Engineering, National Taiwan University, Taipei 10617, Taiwan
}

Available online 17 May 2007

\begin{abstract}
Dye-sensitized solar cells (DSSCs), assembling with nano-crystalline $\mathrm{TiO}_{2}$ adsorbed cis-Ru(dcb) ${ }_{2}(\mathrm{NCS})_{2}$ dye (known as N3) using polar solvent-treated poly(3,4-ethylene dioxythiophene): poly(styrene sulfonate) (PEDOT:PSS) coating on a conductive glass (fluorinedoped tin oxide, FTO) as a counter electrode, were studied. The conductivity of a bare PEDOT:PSS film was only $2 \pm 0.05 \mathrm{~S} / \mathrm{cm}$. However, the conductivities of PEDOT:PSS films treated with dimethyl sulfoxide (DMSO), $N, N$-dimethyl acetamide (DMAc), $N, N$ dimethyl formamide (DMF), and dichloromethane (DMC) reached $85 \pm 15,45 \pm 10,36 \pm 7$, and $20 \pm 6 \mathrm{~S} / \mathrm{cm}$, respectively. In addition, carbon blacks $(0.02,0.1,0.5,1.0,2.0 \mathrm{wt} \%$ with respect to PEDOT:PSS aqueous solution) were added into the DMSO-treated PEDOT:PSS solution (denoted as DMSO-PEDOT:PSS) to enhance the conductivity. Atomic force microscopy (AFM) images of PEDOT:PSS and various DMSO-PEDOT:PSS films coated on the FTO glasses were examined. The topographical images reveal that the increased surface roughness is responsible for the enhanced electrochemical property of the DMSO-PEDOT:PSS films. AC impedance technique was also employed to analyze the kinetics at the electrolyte/counter electrode interface. The DSSC using carbon black $(0.1 \mathrm{wt} \%)$-modified DMSO-PEDOT:PSS conductive coating as a counter electrode reached a cell efficiency of $5.81 \% \mathrm{under} 100 \mathrm{~mW} / \mathrm{cm}^{2}$. This efficiency is higher than a DSSC using Pt as a counter electrode $(5.66 \%)$.
\end{abstract}

(C) 2007 Elsevier B.V. All rights reserved.

Keywords: AC impedance; Dimethyl sulfoxide (DMSO); Dye-sensitized solar cells (DSSCs); PEDOT:PSS; Surface morphology; Surface roughness

\section{Introduction}

Dye-sensitized solar cells (DSSCs) have been widely investigated as a next-generation solar cell because of their simple fabrication process and low costs [1]. A sputtered platinum-conducting glass is usually employed as a counter electrode of the DSSCs to catalyze reduction of $\mathrm{I}_{3}^{-}$to $\mathrm{I}^{-}$in redox electrolyte. However, $\mathrm{Pt}$ is one of the expensive rare metals in the earth; evolution of the counter electrodes with the other cheaper materials expected to reduce production cost of the cells is needed. Therefore, Yohannes and Inganäs [2] had reported that electrochemically polymerized and doped poly(3,4-ethylene dioxythiophene) (PEDOT) can

\footnotetext{
*Corresponding author. Department of Chemical Engineering, National Taiwan University, Taipei 10617, Taiwan.

Tel.: + 886223660739 ; fax: + 886223623040 .

E-mail address: kcho@ntu.edu.tw (K.-C. Ho).
}

catalyze the reaction of $\mathrm{I}_{3}^{-} / \mathrm{I}^{-}$redox couple in DSSCs. Furthermore, the electronically catalytic activity is investigated for conducting polymers recently, such as PEDOT, polypyrrole (PPy) and polyaniline (PANI) substituted for the sputtered platinum counter electrodes of the DSSCs and showed that PEDOT have high room temperature conductivity and remarkable stabilities [3]. In addition, a carbon electrode prepared with an activated carbon was made in order to replace a Pt counter electrode [4].

PEDOT doped with poly(4-styrene sulfonate) (PSS) has attracted much attention during the last decade [5]. However, the films are plagued by a low conductivity, generally $<1 \mathrm{~S} / \mathrm{cm}$, which is lower than that of many conducting polymers by one or two orders of magnitude; this badly affects some of its applications [6]. Recently, it was discovered that the conductivity of a PEDOT:PSS (chemical structure is shown in Scheme 1) film is enhanced by over 100 -folds if a liquid or solid organic compound, 


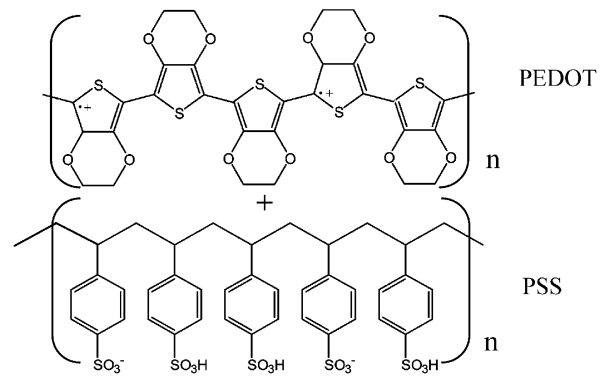

Scheme 1. Chemical structure of PEDOT:PSS.

such as ethylene glycol (EG), glycerol, methyl sulfoxide (DMSO), $N, N$-dimethyl formamide (DMF), sorbitol or tetrahydrofuran (THF), is added to the PEDOT:PSS aqueous solution $[7,8]$. Besides, the choice of preparation method for depositing conducting polymers on the conducting glasses is significant for evaluating the efficiency of the DSSCs. A few methods, for instance spin coating [9] and chemical polymerization $[3,10]$, were employed in order to form a conductive polymer-deposited counter electrode which possesses good electrochemical stability.

In this study, we applied a commercial PEDOT:PSS aqueous solution coating onto a conductive glass (fluorinedoped tin oxide, FTO) as a counter electrode. Furthermore, different organic solvents such as $N, N$-dimethyl acetamide (DMAc), DMF, dichloromethane (DMC), and dimethyl sulfoxide (DMSO) were added into the PEDOT:PSS aqueous solution individually. Besides, in order to enhance the conductivity and roughness of the polymer films, a small amount of carbon blacks is added. All the films were formed by the dip-coating method and dried under air at $80^{\circ} \mathrm{C}$.

\section{Experimental details}

\subsection{Materials}

PEDOT:PSS aqueous solution $(1.3 \mathrm{wt} \%$ dispersion in water), DMAc, DMF, DMC, and DMSO were obtained from Aldrich. Anhydrous lithium iodide (LiI), $\mathrm{I}_{2}$, poly (ethylene glycol) (PEG), and 4-tertiary butylpyridine (TBP) were acquired from Merck. Titanium (IV) isopropoxide (98\%) was purchased from Acros and used as such. $\mathrm{CH}_{3} \mathrm{CN}$ and tertiary butanol were purchased from Merck and water molecules, if any, were removed by putting molecular sieves in the solvent $(4 \AA)$. The ruthenium dye, cis-di(thiocyanato)bis(2,2'-bipyridyl-4,4'-dicarboxylate) ruthenium (II) (N3), was the commercial product obtained from Solaronix S.A., Aubonne, Switzerland. The FTO conducting glasses $\left(R_{\mathrm{sh}}=20-25 \Omega /\right.$ sq. $)$ were obtained from Sinonar Corp., Hsinchu, Taiwan.

\subsection{Preparation of electrodes and the cell assembly}

The preparation of the counter electrodes is as follows: The PEDOT:PSS aqueous solution and the organic solvent were mixed by the volume ratio of 3:1. The solvents used were DMSO, DMAc, DMF, or DMC. The mixed solution of PEDOT:PSS and organic solvent was filtered and stirred continuously for $6 \mathrm{~h}$ at room temperature. The solventtreated PEDOT:PSS films were formed on FTO by dip coating the above-mentioned polymer adhesive solutions. In addition, PEDOT:PSS treated with DMSO, DMAc, DMF, or DMC is henceforth denoted as DMSO-PEDOT:PSS, DMAc-PEDOT:PSS, DMF-PEDOT:PSS, or DMC-PEDOT:PSS, respectively. In order to improve the conductivity and roughness of the films, adding a small amount of carbon blacks $(0.02,0.1,0.5,1.0$, or $2.0 \mathrm{wt} \%$ with respect to the solvent-treated PEDOT:PSS aqueous solution) is required. All of the films were dried at $80^{\circ} \mathrm{C}$ for $30 \mathrm{~min}$ in air.

The preparation of $\mathrm{TiO}_{2}$ paste and the electrode fabrication were carried out based on previous literatures $[11,12]$. Titanium (IV) isopropoxide of $72 \mathrm{ml}$ was added to $430 \mathrm{ml}$ of a $0.1 \mathrm{M}$ nitric acid solution with constant stirring and heated to $85^{\circ} \mathrm{C}$ simultaneously for $8 \mathrm{~h}$. When the mixture was cooled down to room temperature, the resultant colloid was filtered and heated in an autoclave at $240{ }^{\circ} \mathrm{C}$ for $12 \mathrm{~h}$ in order to allow the growth of the $\mathrm{TiO}_{2}$ nanoparticles. The $\mathrm{TiO}_{2}$ colloid was concentrated to $13 \mathrm{wt} \%$, and $30 \mathrm{wt} \%$ (with respect to $\mathrm{TiO}_{2}$ ) of $\mathrm{PEG}$ $(\mathrm{MW}=20,000)$ was added to prevent the film from cracking during drying. The $\mathrm{TiO}_{2}$ paste was deposited using the glass rod method on a conducting FTO glass. The $\mathrm{TiO}_{2}$ thin film was dried in air at room temperature for $30 \mathrm{~min}$, followed by heating the film to $500^{\circ} \mathrm{C}$ at a rate of $20^{\circ} \mathrm{C} / \mathrm{min}$, and maintained for $30 \mathrm{~min}$ before cooling to room temperature. The thickness of the $\mathrm{TiO}_{2}$ film was controlled at $20 \mu \mathrm{m}$ by repeating the above process. The film thickness was measured using a profilometer (Sloan Dektak 3030).

The $\mathrm{TiO}_{2}$ thin films of $0.25 \mathrm{~cm}^{2}$ were selected and the films were immersed in $3 \times 10^{-4} \mathrm{M}$ solution of $\mathrm{N} 3$ dye containing acetonitrile and tertiary butanol (in the volume ratio of 1:1) for overnight. As for the electrolyte to be used in DSSCs, it was composed of $0.5 \mathrm{M} \mathrm{LiI} / 0.05 \mathrm{M}$ iodine $\left(\mathrm{I}_{2}\right) /$ $0.5 \mathrm{M}$ TBP in $\mathrm{CH}_{3} \mathrm{CN}$. The specified composition of the electrolyte was sprayed on both the dye-immobilized $\mathrm{TiO}_{2}$ film and Pt-sputtered or solvent-treated PEDOT:PSS deposited FTO glass, then they were physically sandwiched together using cell holders.

\subsection{Instrumentation}

Cyclic voltammetry (CV) measurements were carried out with a potentiostat/galvanostat (PGSTAT 30, Autolab, Eco-Chemie, the Netherlands) in $0.1 \mathrm{M} \mathrm{KCl}$ solution with an FTO glass substrate coated with the PEDOT:PSS film (or organic solvents-treated PEDOT:PSS film) as the working electrode, a Pt wire as the counter electrode, and $\mathrm{Ag} / \mathrm{AgCl}$ (sat'd $\mathrm{KCl}$ ) as the reference electrode. In addition, the room temperature conductivity of the modified polymer films was measured by the four-point 
probe technique (Model: QT-50, Quatek Co. Ltd., Taiwan) using a Keithley 2000 source meter.

The topography of the polymer films was studied by atomic force microscopy (AFM) with a scanning probe microscope with a NanoScope ${ }^{\circledR}$ IIIa controller operated in tapping mode, equipped with the extended electronics module enabling height imaging in tapping mode. Electrochemical impedance spectroscopy (EIS) was attained with the above-mentioned potentiostat/galvanostat equipped with FRA2 module under a constant light illumination of $100 \mathrm{~mW} / \mathrm{cm}^{2}$. The frequency range explored was $10 \mathrm{mHz}$ to $65 \mathrm{kHz}$. The applied bias voltage, between the FTO-Pt counter electrode (or FTO solvent-treated PEDOT:PSS electrode) and the $\mathrm{FTO}-\mathrm{TiO}_{2}$-dye working electrode, was set at the open-circuit voltage of the DSSCs, with an ac amplitude perturbed at $10 \mathrm{mV}$. The impedance spectra were analyzed by an equivalent circuit model interpreting the characteristics of DSSCs [13,14]. Model parameters were determined by using a nonlinear least-square fitting procedure [15].

The photoelectrochemical characterizations of the DSSCs were accomplished using an AM 1.5-simulated light radiation. The light source was emitted from a $450 \mathrm{~W}$ Xe lamp (Oriel, \#6266) equipped with a water-based IR filter and AM 1.5 filter (Oriel, \#81075). Photoelectrochemical characteristics of the DSSCs, including their opencircuit voltages $\left(V_{\mathrm{oc}}\right)$ and photocurrent-voltage (I-V) curves, were recorded with a potentiostat/galvanostat mentioned earlier.

\section{Results and discussion}

\subsection{Effect of organic solvents on the conductivity of PEDOT:PSS films}

Table 1 shows the room temperature de conductivity $(\sigma)$ of PEDOT:PSS films treated with various organic solvents (DMSO, DMAc, DMF, and DMC). The conductivities of the PEDOT:PSS films prepared from DMSO, DMAc, DMF, and DMC solvents are $85 \pm 15,45 \pm 10$, $36 \pm 7$, and $20 \pm 6 \mathrm{~S} / \mathrm{cm}$, respectively. A PEDOT:PSS film

Table 1

Room temperature conductivity of the PEDOT:PSS film samples treated with various solvents and carbon blacks (C)

Materials (PEDOT:PSS aqueous solution):solvent $=3: 1 \quad$ Conductivity $(\mathrm{S} / \mathrm{cm})$

\section{DMSO-PEDOT:PSS}

DMAc-PEDOT:PSS

DMF-PEDOT:PSS

DMC-PEDOT:PSS

DMSO-PEDOT:PSS (C: $0.02 \mathrm{wt} \%)$

DMSO-PEDOT:PSS (C: $0.1 \mathrm{wt} \%)$

DMSO-PEDOT:PSS (C: $0.5 \mathrm{wt} \%)$

DMSO-PEDOT:PSS (C: $1.0 \mathrm{wt} \%)$

DMSO-PEDOT:PSS (C: $2.0 \mathrm{wt} \%$ )

Bare PEDOT:PSS treated with DMSO exhibits the highest conductivity. By contrast, a bare PEDOT:PSS film possesses poor conductivity of only $2 \pm 0.05 \mathrm{~S} / \mathrm{cm}$. In addition, the room temperature dielectric constants for DMSO, DMAc, DMF, and DMC are 49, 38.9, 36.7, and 3.1, respectively, characterizing the dipole moment of the solvent molecules [7]. Polar solvents with higher dielectric constants such as DMSO induce the strong screening effect between counter ions and charge carriers, which reduces the Coulombic interaction between positively charged PEDOT and negatively charged PSS dopants. Therefore, the screening effect enhances the hopping rate and conductivity in the PEDOT/PSS systems [7].

As for the addition of carbon black, a higher conductivity of the film is attained as expected. The conductivities of DMSO-PEDOT:PSS solutions containing carbon blacks at $0.02,0.1,0.5,1.0,2.0 \mathrm{wt} \%$ (with respect to the solvent-treated PEDOT:PSS aqueous solution) reached $95 \pm 9,105 \pm 10,185 \pm 15,280 \pm 10$, and $350 \pm 15 \mathrm{~S} / \mathrm{cm}$, respectively. However, the films of DMSO-PEDOT:PSS added with over $0.5 \mathrm{wt} \%$ carbon black crack easily during manipulations as a result of failure of adhesive force. For this reason, choices of 0.02 and $0.1 \mathrm{wt} \%$ carbon blacks are suitable for further study.

\subsection{Cyclic voltammetry $(\mathrm{CV})$}

The effect of solvent on the electrochemical behavior of various PEDOT:PSS films was studied by $\mathrm{CV}$ in a $0.1 \mathrm{M}$ $\mathrm{KCl}$ aqueous solution. As a DMSO-treated film gives the highest conductivity among others, Fig. 1 only shows the CV results for the PEDOT:PSS and DMSO-PEDOT:PSS films for simplicity. The bare PEDOT:PSS film exhibits redox behavior at a potential more positive than $-0.2 \mathrm{~V}$ vs. $\mathrm{Ag} / \mathrm{AgCl}$ (sat'd $\mathrm{KCl}$ ). Furthermore, the current density integrated over the interested potential range was nearly doubled after treating with DMSO and tested at a scan rate

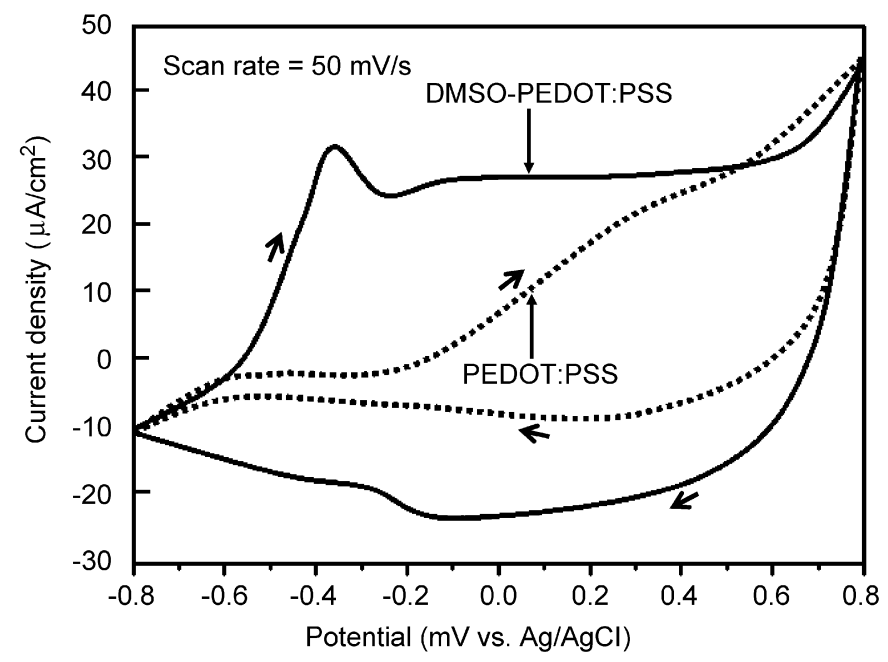

Fig. 1. Cyclic voltammograms of PEDOT:PSS (dash lines) and DMSOPEDOT:PSS film. Scan rate: $50 \mathrm{mV} / \mathrm{s}$. Reference electrode: $\mathrm{Ag} / \mathrm{AgCl}$ (sat'd $\mathrm{KCl})$. 
of $50 \mathrm{mV} / \mathrm{s}$. The enhanced electrochemical activity for the DMSO-treated counter electrodes is subject to further morphological examination by AFM.

\subsection{Surface morphology of PEDOT:PSS films}

Fig. 2 shows high-resolution tapping-mode AFM images of PEDOT:PSS and various DMSO-PEDOT:PSS films coated on the FTO glasses. It is observed that the surface morphology of a bare PEDOT:PSS film is very smooth (with a mean roughness of only $2.0 \mathrm{~nm}$ ), as seen in Fig. 2(a). However, the mean roughnesses of the DMSOPEDOT:PSS and DMSO-PEDOT:PSS (C: 0.02 and $0.1 \mathrm{wt} \%$ ) films are larger than that of the PEDOT:PSS film. The AFM result supports that the increased surface roughness or higher surface area is responsible for the enhanced electrochemical property of the DMSO-PEDOT:PSS films. This implies that the charge-transfer resistance at the DMSO-treated counter electrode/electro- lyte interface would be lower, as more reaction sites are available for reducing $\mathrm{I}_{3}^{-}$to form $\mathrm{I}^{-}$in the electrolyte.

\subsection{EIS of the DSSC}

The EIS technique had been used to characterize the kinetics of the DSSCs by analyzing the variation in impedances associated with different cell configurations $[16,17]$. In this work, the analysis was mainly aimed at the Nyquist plots associated with a solvent-treated PEDOT:PSS film as a counter electrode measuring at the open-circuit voltage under illumination of simulated AM 1.5 solar light $\left(100 \mathrm{~mW} \mathrm{~cm}^{-2}\right)$.

Fig. 3 shows the equivalent circuit and typical impedance spectra of a DSSC with a Pt, bare or solvent-modified PEDOT:PSS counter electrode. Experimental data are represented by symbols while the solid lines correspond to the fit using the equivalent circuit model proposed in the inset. Three semicircles are clearly observed in the
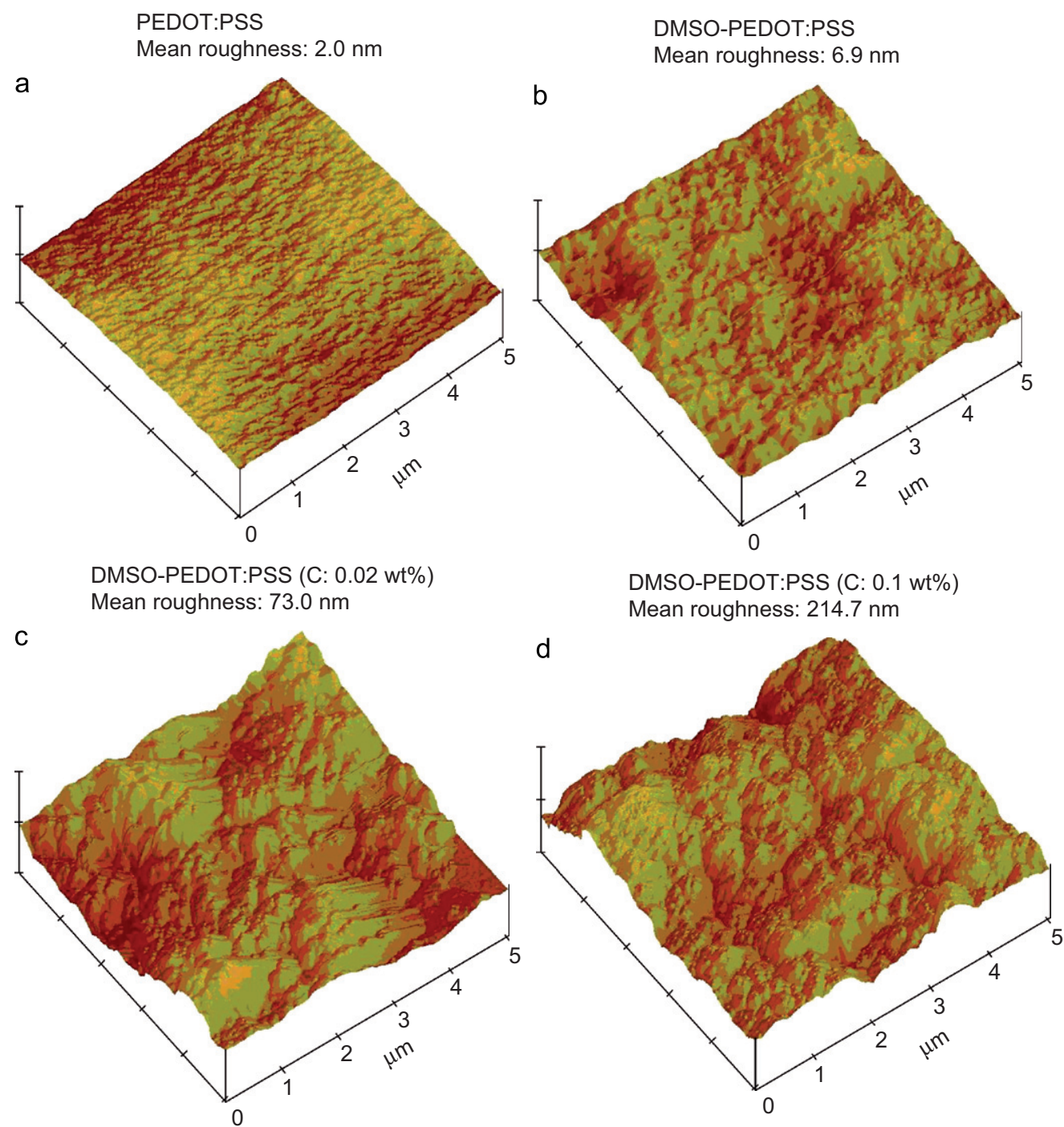

Fig. 2. AFM images $(5 \mu \mathrm{m} \times 5 \mu \mathrm{m})$ of polymer films coating on FTO glasses. (a) PEDOT:PSS; (b) DMSO-PEDOT:PSS; (c) DMSO-PEDOT:PSS (C: $0.02 \mathrm{wt} \%)$; (d) DMSO-PEDOT:PSS (C: $0.1 \mathrm{wt} \%)$. 


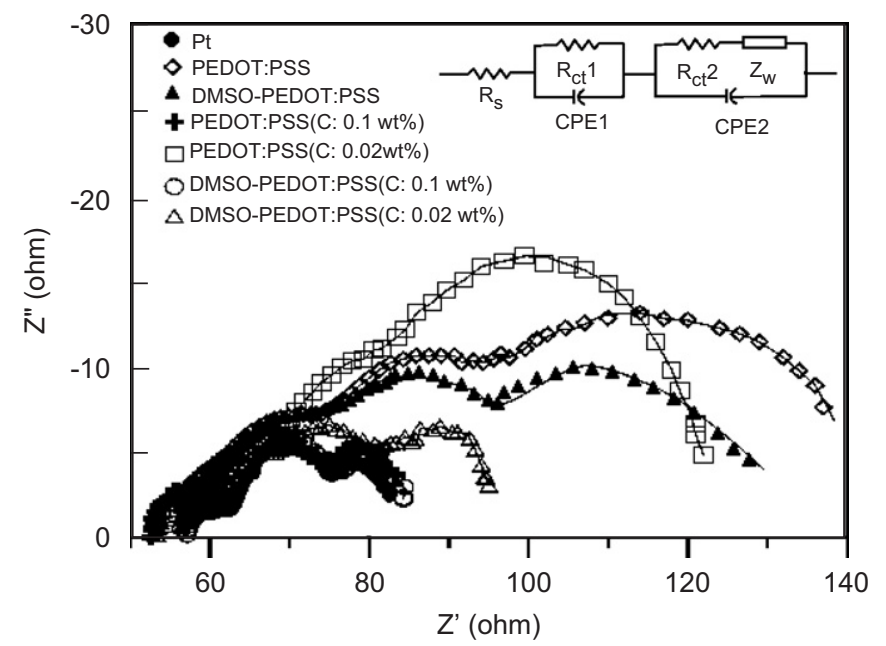

Fig. 3. EIS spectra of the DSSC assembled with modified PEDOT:PSS counter electrode under illumination of simulated AM 1.5 solar light $\left(100 \mathrm{~mW} \mathrm{~cm}^{-2}\right)$.

measured frequency range of $10 \mathrm{mHz}-65 \mathrm{kHz}$. The ohmic serial resistance $\left(R_{\mathrm{S}}\right)$ corresponds to the electrolyte and the FTO resistance and the resistances $R_{\mathrm{ct} 1}, R_{\mathrm{ct} 2}$, and $R_{\mathrm{diff}}$ relate to charge-transfer processes occurring at the counter electrode, dye-sensitized $\mathrm{TiO}_{2}$ electrode, and Nernstian diffusion within the electrolyte, respectively [18]. The impedance for the Warburg diffusion, $Z_{\mathrm{w}}$, in a finite region of length $l_{\mathrm{e}}$ (which might be the thickness between the electrodes) can be expressed by Eq (1),

$Z_{\mathrm{w}}=R_{\text {diff }}\left\{\left[\tanh (j \omega \tau)^{1 / 2}\right] /(j \omega \tau)^{1 / 2}\right\}$

where $\tau=l_{\mathrm{e}}^{2} / D, \omega$ is angle frequency, and $D$ is the diffusion coefficient of the diffusing species [19].

The impedance parameters, obtained by fitting the experimental spectra with the equivalent circuit, are shown in Table 2. It is noted that $R_{\mathrm{ct} 1}(19.4 \Omega)$ of a DMSOPEDOT:PSS film is little bit smaller than that of a bare PEDOT:PSS film $(21.2 \Omega)$ as the counter electrode. Furthermore, the values of $R_{\mathrm{ct} 1}$ for PEDOT:PSS (C: $0.1 \mathrm{wt} \%$ ) and DMSO-PEDOT:PSS (C: $0.1 \mathrm{wt} \%$ ) films are 7.8 and $7.2 \Omega$, respectively. Consequently, a PEDOT:PSS thin film containing carbon blacks can efficiently induce the reduction of $\mathrm{I}_{3}^{-}$to $\mathrm{I}^{-}$in the electrolyte.

\subsection{Photovoltaic performance of DSSCs}

Fig. 4 shows the I-V characteristics of the DSSCs with the counter electrodes made of Pt, PEDOT:PSS, DMSOPEDOT:PSS, PEDOT:PSS (C: $0.1 \mathrm{wt} \%$ ), and DMSOPEDOT:PSS (C: $0.1 \mathrm{wt} \%$ ). Table 3 summarizes the performance data of all cells under AM 1.5 irradiation. For a DSSC containing the PEDOT:PSS counter electrode, it is seen from Table 3 that the photoelectrochemical characteristics, including the short-circuit current density $\left(J_{\mathrm{sc}}\right)$, the open-circuit voltage $\left(V_{\mathrm{oc}}\right)$, the fill factors $(\mathrm{FF})$, and the conversion efficiency $(\eta)$ are $11.16 \mathrm{~mA} / \mathrm{cm}^{2}, 0.71 \mathrm{~V}$, $0.24 \%$ and $1.90 \%$, respectively; in contrast, a DSSC
Table 2

EIS parameters of the DSSC assembled with all counter electrodes used in the study, including Pt, PEDOT:PSS, and DMSO-treated PEDOT:PSS at various $\mathrm{C}$ contents

\begin{tabular}{lccc}
\hline Counter electrode & $R_{\mathrm{ct} 1}(\Omega)$ & $R_{\mathrm{ct} 2}(\Omega)$ & $R_{\mathrm{diff}}(\Omega)$ \\
\hline Pt & 7.5 & 8.3 & 6.5 \\
PEDOT:PSS & 21.2 & 14.5 & 39.4 \\
DMSO-PEDOT:PSS & 19.4 & 11.1 & 20.1 \\
PEDOT:PSS (C: $0.1 \mathrm{wt} \%)$ & 7.8 & 9.5 & 9.8 \\
PEDOT:PSS (C: $0.02 \mathrm{wt} \%)$ & 18.9 & 13.1 & 34.5 \\
DMSO-PEDOT:PSS (C: $0.1 \mathrm{wt} \%)$ & 7.2 & 8.5 & 7.1 \\
DMSO-PEDOT:PSS (C: $0.02 \mathrm{wt} \%)$ & 13.6 & 9.8 & 15.2 \\
\hline
\end{tabular}

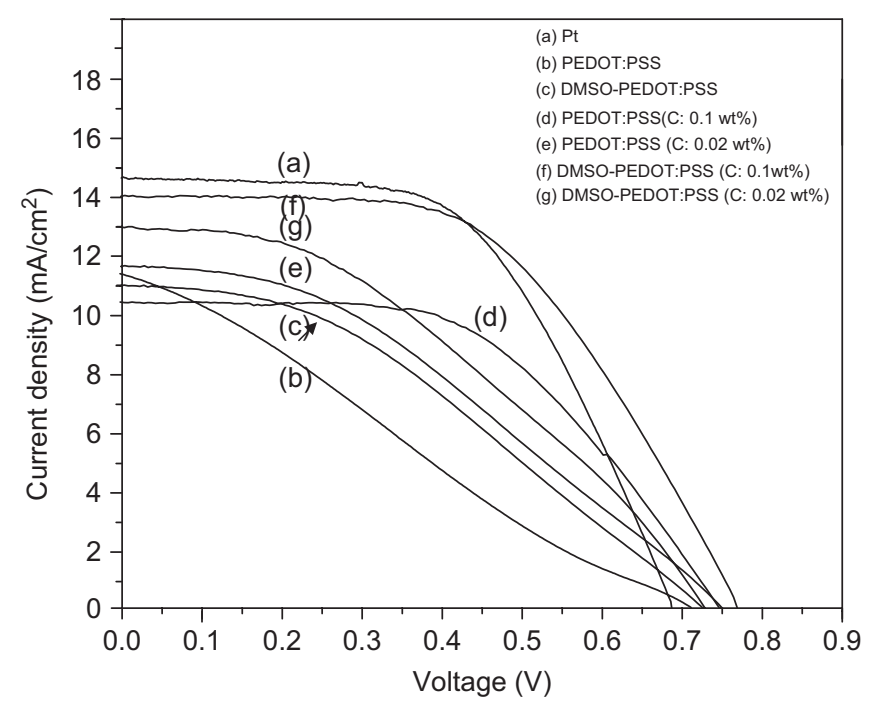

Fig. 4. Photovoltaic characteristics of the DSSCs using Pt or modified PEDOT:PSS counter electrode under light illumination of $100 \mathrm{~mW} / \mathrm{cm}^{2}$. The electrolyte was composed of $0.5 \mathrm{M}$ lithium iodide (LiI) $/ 0.05 \mathrm{M}$ iodine $\left(\mathrm{I}_{2}\right) / 0.5 \mathrm{M}$ tertiary butylpyridine (TBP) in $\mathrm{CH}_{3} \mathrm{CN}$.

Table 3

The performance of the DSSC with all counter electrodes used in the study, including Pt, PEDOT:PSS, and DMSO-treated PEDOT:PSS at various $\mathrm{C}$ contents

\begin{tabular}{lllll}
\hline Counter electrode & $J_{\mathrm{sc}}\left(\mathrm{mA} / \mathrm{cm}^{2}\right)$ & $V_{\mathrm{oc}}(\mathrm{V})$ & $\mathrm{FF}$ & $\eta(\%)$ \\
\hline $\mathrm{Pt}$ & 14.64 & 0.68 & 0.57 & 5.66 \\
PEDOT-PSS & 11.16 & 0.71 & 0.24 & 1.90 \\
DMSO-PEDOT:PSS & 11.01 & 0.73 & 0.30 & 2.41 \\
PEDOT:PSS (C: $0.1 \mathrm{wt} \%)$ & 10.44 & 0.75 & 0.54 & 4.17 \\
PEDOT:PSS (C: $0.02 \mathrm{wt} \%)$ & 10.64 & 0.74 & 0.57 & 3.21 \\
DMSO-PEDOT:PSS (C: $0.1 \mathrm{wt} \%)$ & 14.05 & 0.78 & 0.53 & 5.81 \\
DMSO-PEDOT:PSS (C: $0.02 \mathrm{wt} \%)$ & 13.08 & 0.75 & 0.56 & 3.64 \\
\hline
\end{tabular}

containing the DMSO-PEDOT:PSS counter electrode possesses higher efficiency $(2.41 \%)$. When a suitable amount $(0.1 \mathrm{wt} \%)$ of carbon black was added to the PEDOT:PSS dispersion in a water-DMSO binary solvent, the $I-V$ characteristics were dramatically improved, and the conversion efficiency of a DSSC made of a DMSOPEDOT:PSS (C: $0.1 \mathrm{wt} \%$ ) film as the counter electrode reached $5.81 \%$, which is slightly higher than that obtained 
with a DSSC using a Pt counter electrode (5.66\%). Consequently, DMSO plays a role in enhancing conductivity of a PEDOT:PSS film; moreover, carbon black plays vital parts in further increasing the catalytic activity of the film due to its larger surface area.

\section{Conclusions}

The conductivity of the PEDOT:PSS films treated with DMSO exhibits the highest conductivity of $85 \pm 15 \mathrm{~S} / \mathrm{cm}$ among various solvents studied. According to the AFM study, it is observed that the surface roughnesses of the DMSO-PEDOT:PSS and DMSO-PEDOT:PSS (C: 0.02 and $0.1 \mathrm{wt} \%$ ) films are larger than that of the PEDOT:PSS film. The AFM images suggest that the increased surface roughness, or higher surface area, is responsible for the enhanced electrochemical property of the DMSO-PEDOT:PSS films, as confirmed by the CV. Although the EIS analysis on the equivalent circuit parameters shows that the cell assembled with the DMSO-PEDOT:PSS (C: $0.1 \mathrm{wt} \%$ ) counter electrode is similar to the cell assembled with the $\mathrm{Pt}$ counter electrode, and yet, the best performed DSSC was obtained by using a DMSO-PEDOT:PSS (C: $0.1 \mathrm{wt} \%$ ) counter electrode. This is attributed to the low chargetransfer resistance and the low Nernstian diffusion resistance under AM 1.5 light illumination at $100 \mathrm{~mW} / \mathrm{cm}^{2}$.

\section{Acknowledgements}

This work was financially supported by the Academia Sinica, Taipei, Taiwan, the Republic of China, under Grant AS-94-TP-A02. This work was partially supported by the Photovoltaics Technology Center, Industrial Technology Research Institute (ITRI), Chutung, Hsinchu, Taiwan.

\section{References}

[1] B. O'Regan, M. Grätzel, Nature 353 (1991) 737.

[2] T. Yohannes, O. Inganäs, Sol. Energy Mater. Sol. Cells 51 (1998) 193.

[3] L. Bay, K. West, B.W. Jensen, T. Jacobsen, Sol. Energy Mater. Sol. Cells 90 (2006) 341.

[4] K. Imoto, K. Takahashi, T. Yamaquchi, T. Komura, J.I. Nakamura, K. Murata, Sol. Energy Mater. Sol. Cells 79 (2003) 459.

[5] G. Heywang, F. Jonas, Adv. Mater. 4 (1992) 116.

[6] F. Zhang, M. Johansson, M.R. Andersson, J.C. Hummelen, O. Inganäs, Adv. Mater. 14 (2002) 662.

[7] J.Y. Kim, J.H. Jung, D.E. Lee, J. Joo, Synth. Met. 126 (2002) 311.

[8] J. Ouyang, Q. Xu, C.W. Chu, Y. Yang, G. Li, J. Shinar, Polymer 45 (2004) 8443.

[9] Y. Saito, W. Kubo, T. Kitamura, Y. Wada, S. Yanagida, J. Photochem. Photobiol. A-Chemistry 164 (2004) 153.

[10] D.M. de Leeuw, P.A. Kraakman, P.F.G. Bongaerts, C.M.J. Mutsaers, D.B.M. Klaassen, Synth. Met. 66 (1994) 263.

[11] C.J. Barbé, F. Árendse, P. Comte, M. Jirousek, F. Lenzmann, V. Shklover, M. Grätzel, J. Am. Ceram. Soc. 80 (1997) 3157.

[12] M.K. Nazeeruddin, R. Humphry-Baker, P. Liska, M. Grätzel, J. Phys. Chem. B 107 (2003) 8981.

[13] C. Longo, J. Freitas, M.A. De Paoli, J. Photochem. Photobiol. A 159 (2003) 33

[14] M.C. Bernard, H. Cachet, P. Falaras, A. Hugot-Le Goff, M. Kalbac, I. Lukes, N.T. Oanh, T. Stergiopoulos, I. Arabatzis, J. Electrochem. Soc. 150 (2003) E155.

[15] S. Chengwu, D. Songyuan, W. Kongjia, P. Xu, G. Li, Z. Longyue, H. Linhua, F. Fantai, Sol. Energy Mater. Sol. Cells 86 (2005) 527.

[16] R. Kern, R. Sastrawan, J. Ferber, R. Stangl, J. Luther, Electrochim. Acta 47 (2002) 4213.

[17] L. Han, N. Koide, Y. Chiba, T. Mitate, Appl. Phys. Lett. 84 (2004) 2433.

[18] C. Longo, A.F. Nogueira, M.A. De Paoli, J. Phys. Chem. B 106 (2002) 5925.

[19] J.R. Macdonald, Impedance Spectroscopy, John Wiley, New York, 1987. 